\title{
Speech Intelligibility in Persian Hearing Impaired Children with Cochlear Implants and Hearing Aids
}

\author{
Mohammad Rezaei ${ }^{1}$, Maryam Emadi ${ }^{2}$, Peyman Zamani $^{3}$, Farhad Farahani ${ }^{4}$, and Gohar Lotfi ${ }^{1}$ \\ ${ }^{1}$ Departments of Speech Therapy, ${ }^{2}$ Audiology, Hamadan University of Medical Sciences, Hamadan, \\ ${ }^{3}$ Musculoskeletal Rehabilitation Research Center, Ahvaz Jundishapur University of Medical Sciences, Ahvaz, \\ ${ }^{4}$ Hearing Disorders Research Center, Hamadan University of Medical Sciences, Hamadan, Iran
}

\author{
Received October 13, 2016 \\ Revised December 3, 2016 \\ Accepted January 8, 2017
}

The aim of present study is to evaluate and compare speech intelligibility in hearing impaired children with cochlear implants $(\mathrm{Cl})$ and hearing aid $(\mathrm{HA})$ users and children with normal hearing (NH). The sample consisted of 45 Persian-speaking children aged 3 to 5 -years-old. They were divided into three groups, and each group had 15, children, children with $\mathrm{Cl}$ and children using hearing aids in Hamadan. Participants was evaluated by the test of speech intelligibility level. Results of ANOVA on speech intelligibility test showed that $\mathrm{NH}$ children had significantly better reading performance than hearing impaired children with $\mathrm{Cl}$ and HA. Post-hoc analysis, using Scheffe test, indicated that the mean score of speech intelligibility of normal children was higher than the $\mathrm{HA}$ and $\mathrm{Cl}$ groups; but the difference was not significant between mean of speech intelligibility in children with hearing loss that use cochlear implant and those using HA. It is clear that even with remarkabkle advances in HA technology, many hearing impaired children continue to find speech production a challenging problem. Given that speech intelligibility is a key element in proper communication and social interaction, consequently, educational and rehabilitation programs are essential to improve speech intelligibility of children with hearing loss.

J Audiol Otol 2017;21(1):57-60

KEY WORDS: Hearing impaired children · Hearing aid · Cochlear implant · Speech intelligibility.

\section{Introduction}

Speech intelligibility and speech production in humans are associated with auditory perception. The process of speech intelligibility is incomplete in pre-linguistic deafness or hearing loss occurred before the age 5 ; because such people are not able to hear their own voice and others' and lack the mental background for hearing sounds [1]. In the recent years, advances in technology and hearing equipment provided an excellent opportunity to improve the auditory performance and speech intelligibility [2]. Cochlear implant is a new technology in hearing equipment and an accepted treatment method for children with severe to profound sensorineural

This is an Open Access article distributed under the terms of the Creative Commons Attribution Non-Commercial License (http://creativecommons.org/licenses/by-nc/4.0/) which permits unrestricted non-commercial use, distribution, and reproduction in any medium, provided the original work is properly cited. deafness [3]. Another hearing tool that is older than cochlear implants (CI) is the hearing aid (HA). HA is an electronic device that amplifies sound and is the best HA for hearing impaired people [4]. Using hearing aids or after cochlear implant surgery, the lost hearing ability of deaf people can be restored to a significant extent. It is expected that, over time, their speech intelligibility improves as well [5]. The results of research on the benefits of $\mathrm{CI}$ and hearing aids in children with hearing loss have shown that the age of child at the time of surgery or utilizing hearing aids and the duration of using prosthesis is important in improving speech intelligibility and comprehension [6-8]. Various studies have shown that the use of CI in deaf children can improve speech intelligibility, but speech intelligibility in normal children is better than implanted children $[9,10]$. Most and Peled investigated understanding speech prosodic characteristics between a group of children with CI and two groups of hearing aids users with severe and profound 
hearing loss. The results showed that both groups of children using hearing aids had a better performance in understanding the prosodic features compared to cochlear implant children [11].

Detailed and quantitative scrutiny of hearing impaired children has a significant role in the design of training programs for them, to improve speech intelligibility and verbal communication with others. Due to the inadequacy of studies on speech intelligibility in hearing impaired children in Persian language, the aim of this study is to evaluate and compare speech intelligibility in hearing impaired children with CI, HA users and children with normal hearing.

\section{Subjects and Methods}

\section{Subjects}

The study was corss-sectional and used comparative analytic method. The sample consisted of 45 Persian-speaking children aged 3 to 5-years-old. Participants were divided in three groups of 15 , including normal children, children with $\mathrm{CI}$ and children using hearing aids in Hamadan. All hearingimpaired children with CI at Niusha Center in Hamadan were evaluated in the form of census, after considering the inclusion and exclusion criteria that 15 children were enrolled in the study. A similar number of hearing-impaired children using hearing aids that were matched in terms of age were selected. 15 normal children, from kindergarten living near the Niusha Center geographic region were selected and matched in terms of age with two hearing impaired groups.

Children with CI and hearing aids showed a sensorineural hearing loss in the range of 70 to $90+\mathrm{dB}$. Children with CI and hearing aids were using prosthesis since they were 2 or 3 -years-old. The age of study was 3 and 2, respectively and the use of the prosthesis lasted from 10 to 30 months. The IQ was tested in all three groups based on nonverbal Wechsler test and found to be in the normal range; also, their parents were hearing. The inclusion criteria for hearing impaired children were that the onset of hearing impairment must had occurred under the age of three and had an unaided hearing loss at least 71 in the better ear. The selection criteria for CI children were that No previous cochlear implant experience in either ear and the age of cochlear implantation was when they were 2-years-old. Exclusion criteria included any other disability such as blindness, mental retardation and behavioral disorders.

\section{Materials}

The following instruments were used to collect data:

Wechsler Intelligence Test: Psychologists used Persian version of Wechsler Intelligence Scale for Children-revised to assess the intelligence quotient [12].

Test of speech intelligibility level: This test was designed for use in Persian-speaking children aged 3 to 5 years with hearing loss. The test consists of 29 images made by Heydari, et al. [13]. The pictures have been chosen in a way that all Farsi phonemes are included (Table 1). It is a 3-point scale that requires the clinician to rate speech intelligibility level ( $1=$ not intelligible speech, $2=$ to some extent intelligible speech, $3=$ intelligible speech). Content validity index of selected words was obtained $75 \%$ for test that is good.

\section{Experimental procedures}

The test was conducted in a quiet environment after communication with children and providing the appropriate conditions for maximum responsiveness of the child. The entire assessment session for each child was audio recorded by a digital recorder in a quiet room, and all children were as-

Table 1. Persian speech intelligibility test presented phonetically

\begin{tabular}{|c|c|c|}
\hline Number & Word [in English] & Number of syllables \\
\hline 1 & $\mathrm{~Pa}$ [foot] & 1 \\
\hline 2 & Sib [apple] & 1 \\
\hline 3 & Mouz [banana] & 1 \\
\hline 4 & Kif [bag] & 1 \\
\hline 5 & Mouš [mouse] & 1 \\
\hline 6 & Tut [berry] & 1 \\
\hline 7 & Gol [flower] & 1 \\
\hline 8 & Keik [cake] & 1 \\
\hline 9 & Daest [hand] & 1 \\
\hline 10 & Mahi [fish] & 1 \\
\hline 11 & Deraext [tree] & 2 \\
\hline 12 & Lakpošt [turtle] & 2 \\
\hline 13 & Mesvak [toothbrush] & 2 \\
\hline 14 & Qeyči [scissor] & 2 \\
\hline 15 & Kelid [key] & 2 \\
\hline 16 & Xiyar [cucumbers] & 2 \\
\hline 17 & Livan [glass] & 2 \\
\hline 18 & Čaengal [fork] & 2 \\
\hline 19 & Dočarxe [bicycle] & 3 \\
\hline 20 & Zaerrafe [giraffe] & 3 \\
\hline 21 & Qurbaqe [frog] & 3 \\
\hline 22 & Porteqal [orange] & 3 \\
\hline 23 & Otobus [bus] & 3 \\
\hline 24 & Saendali [chair] & 3 \\
\hline 25 & Padaembaerfi [snowman] & 4 \\
\hline 26 & Sibzamini [potato] & 4 \\
\hline 27 & Macaroni & 4 \\
\hline 28 & Tutfarangi [strawberry] & 4 \\
\hline 29 & Haevapeyma [plane] & 4 \\
\hline
\end{tabular}


Table 2. Descriptive information of subjects

\begin{tabular}{|c|c|c|c|c|c|c|c|c|c|c|c|}
\hline \multirow{2}{*}{ Groups } & \multicolumn{2}{|c|}{ Gender } & \multicolumn{4}{|c|}{ Age } & \multirow{2}{*}{$\begin{array}{l}\text { Hearing } \\
\text { loss }(\mathrm{dB})\end{array}$} & \multirow{2}{*}{$\begin{array}{l}\text { Duration of } \\
\text { device use }\end{array}$} & \multirow{2}{*}{$\begin{array}{c}\text { Age of diagnosis } \\
\text { (month) }\end{array}$} & \multicolumn{2}{|c|}{ Nature of HL (\%) } \\
\hline & Male & Female & Min & Max & Mean & SD & & & & Congenital & Prelingual \\
\hline Cochlear implant & 8 & 7 & 37 & 65 & 52.18 & 10.13 & 88.70 & 81.08 & 11.41 & 75 & 25 \\
\hline Hearing aid & 8 & 7 & 37 & 64 & 52.90 & 9.64 & 88.33 & 82.58 & 11.16 & 70.83 & 29.16 \\
\hline Normal & 8 & 7 & 36 & 65 & 52.63 & 10.67 & & & & & \\
\hline$p$ & & & & & & & $p=0.502$ & $p=0.348$ & & & \\
\hline
\end{tabular}

HL: hearing loss, SD: standard deviation

sessed separately. All produced words were saved in a computer for the listening session. Every single picture of speech intelligibility test was shown to the child and after naming it, three speech and language pathologist (SLPs) gave their judgment upon clarity or vagueness of the child's speech. If at least two SLPs gave similar judgment about speech intelligibility level of each produced word, given point was accepted. After the images were finished, the child's speech intelligibility was calculated as a percentage by each SLP and the average percentage was recorded as the final percentage of speech intelligibility.

The obtained data were analyzed in SPSS version16 (IBM Corp., Armonk, IL, USA) using one-way analysis of variance and Scheffe post hoc test.

\section{Results}

The average age of hearing-impaired children with CI was $52.18 \pm 10.13$ months and the mean age of children with HA was $52.90 \pm 9.64$ months, which were not significantly different $(p=0.986)$. Table 2 shows demographic information including duration of device use, the mean chronological age, hearing loss severity, child's age at onset of hearing loss, nature of loss, and duration using of device use. In Table 3, the mean and standard deviation of speech intelligibility is shown in all three groups.

Results of ANOVA show that speech intelligibility scores have a significant difference in the studied groups $(\mathrm{F}=8.57$ and $p<0.001$ ).

Post hoc analysis using Scheffe test indicated that the mean score of speech intelligibility of normal children was higher than the HA ( $p=0.003)$ and CI $(p=0.009)$ groups; but the difference was not significant between mean of speech intelligibility in children with hearing loss that use cochlear implant and those using HA $(p=0.901)$.

\section{Discussion}

The results showed that the mean scores of speech intelligibility in hearing impaired children with CI or hearing aids
Table 3. Mean and SD for speech intelligibility score

\begin{tabular}{|c|c|c|c|c|c|c|}
\hline \multirow[t]{2}{*}{ Variable } & \multicolumn{2}{|c|}{$\begin{array}{l}\text { Cochlear } \\
\text { implant }\end{array}$} & \multicolumn{2}{|c|}{ Hearing aid } & \multicolumn{2}{|c|}{ Normal } \\
\hline & Mean & SD & Mean & SD & Mean & SD \\
\hline $\begin{array}{c}\text { Speech } \\
\text { intelligibility }\end{array}$ & 72.31 & 23.42 & 68.94 & 17.58 & 96.90 & 6.20 \\
\hline
\end{tabular}

have significant differences with that of normal children. So that children with normal hearing had clear speech, better than hearing-impaired children. These results are consistent with findings of Habib, et al. [14] that speech intelligibility is better in children with normal hearing compared to children with cochlear implant.

Lee, et al. [15] also suggest that the performance of cochlear implanted children in understanding the pitch and speech intelligibility was significantly lower than normal children; this finding is consistent with our results.

As the hearing input rate becomes greater, speech production performance will be better and will recieve more auditory feedback; hence, it can be predicted that hearing loss can cause weakness in speech intelligibility [16]. Since the lost hearing of hearing impaired people with cochlear implant or HA is compensated dramatically, their hearing performance improves over time, resulting in improved speech intelligibility. However, given that they have not received adequate auditory input during the sensitive period of language-learning (less than 2-years-old) one cannot expect them to show similar performance of hearing people [17].

Other results of this study showed that speech intelligibility in children with CI and children with HA had no significant difference. This is consistent with results of Shamsian, et al. [18], that speech intelligibility in first and second years of cochlear implant has no significant increase. Also, it is consistent with the study of Most and Peled [11], they determined that speech prosodic features in children with implanted cochlear have no advantage over the hearing aids users.

On the last result of this study, it can be said that the current cochlear implant devices have limitations in transfer of data and the acuity or pitch of speech. Implant users often creates difficulty at low frequencies for people and they don't 
receive appropriate information, and do not have proper processing, therefore weakness in speech intelligibility can be expected $[19,20]$.

Given that speech intelligibility test was used in this study, and regarding the limits on the number of people having planted, generalization of the results should be done with caution. It is suggested that future research is conducted on the speech intelligibility in narrative speech and on more people. In conclusion the results of this study suggest that speech intelligibility of normal children is significantly better than children with hearing loss. But there was no significant difference in the speech intelligibility performance in terms of the type of used hearing device in children with hearing loss (CI or hearing aids). Considering the findings, cochlear implantation is not significantly more effective than HA for improvement of speech intelligibility. It is clear that even with remarkabkle advances in HA technology, many deaf children continue to find speech production a challenging problem. Given that speech intelligibility is a key element in proper communication and social interaction, consequently, educational and rehabilitation programs are essential to improve speech intelligibility of children with hearing loss.

\section{Acknowledgments}

This work was supported by a grant from the Hamadan university of Medical Sciences and Health Services. Deputy of Research (Grant Reference Number: 9207232339).

\section{Conflicts of interest}

The authors have no financial conflicts of interest.

\section{REFERENCES}

1) Khalesi MH, Amirfattahi R, Khorsandi MT, Motesaddi M, Abdi S. Effect of auditory feedback on speech production after cochlear implantation. Tehran Univ Med J 2001;59:1-9.

2) Peng SC, Tomblin JB, Turner CW. Production and perception of speech intonation in pediatric cochlear implant recipients and individuals with normal hearing. Ear Hear 2008;29:336-51.

3) Roohparvar R, Bijankhan M, Hasanzadeh S, Jalaie S. The acoustic analysis of voice onset time in cochlear implanted children and normal-hearing controls. Bimon Audit Tehran Univ Med Sci 2010;19: 39-49.

4) Gelfand SA. Essentials of Audiology. 3rd ed. New York: Thieme; 2009. p.245-7.

5) Zamani P, Rahmanirasa A, Weisi F, Valadbeigi A, Farahani F, Rezaei M. Vowel production in persian deaf children with cochlear implant: is the age of implantation an important factor? Indian J
Otolaryngol Head Neck Surg 2014;66:407-13.

6) Weisi F, Rezaei M, Rashedi V, Heidari A, Valadbeigi A, EbrahimiPour M. Comparison of reading skills between children with cochlear implants and children with typical hearing in Iran. Int J Pediatr Otorhinolaryngol 2013;77:1317-21.

7) Weisi F, Rezaei M, Valadbeigi A. The effect of the age of cochlear implantation on the reading skills of children with hearing loss. J Res Rehabil Sci 2013;9:553-60.

8) Rezaei M, Rashedi V, Morasae EK. Reading skills in Persian deaf children with cochlear implants and hearing aids. Int J Pediatr Otorhinolaryngol 2016;89:1-5.

9) Zamani P, Zarandy MM, Borghei P, Rezai H, Moubedshahi F. The role of age implantation on formants frequency changing in early and late cochlear implanted children: a study based on perceptual and acoustical assessments. Audi Vestib Res 2016;25:24-31.

10) Mahmoudi Z, Rahati S, Ghasemi M, Rajati M, Asadpour V, Tayerani H. Diagnosis of voice abnormalities in speech of children with cochlear implant and Hearing aid with artificial decision making systems. Med Sci J Islam Azad Univ Mashhad Branch 2009;5:6778.

11) Most T, Peled M. Perception of suprasegmental features of speech by children with cochlear implants and children with hearing AIDS. J Deaf Stud Deaf Educ 2007;12:350-61.

12) Razavieh A, Shahim S. Standardization of Wechsler intelligence scale revised for children in Iran. Shiraz: Shiraz University Publication;2008.

13) Heydari S, Torabi Nezhad F, Agha Rasouli Z, Hoseyni F. Development of speech intelligibility measurement test for 3 to 5 years old normal children. Bimon Audit Tehran Univ Med Sci 2011;20:47-53.

14) Habib MG, Waltzman SB, Tajudeen B, Svirsky MA. Speech production intelligibility of early implanted pediatric cochlear implant users. Int J Pediatr Otorhinolaryngol 2010;74:855-9.

15) Lee KY, van Hasselt CA, Chiu SN, Cheung DM. Cantonese tone perception ability of cochlear implant children in comparison with normal-hearing children. Int J Pediatr Otorhinolaryngol 2002;63: 137-47.

16) Phillips L, Hassanzadeh S, Kosaner J, Martin J, Deibl M, Anderson I. Comparing auditory perception and speech production outcomes: non-language specific assessment of auditory perception and speech production in children with cochlear implants. Cochlear Implants Int 2009;10:92-102.

17) Rezaei M, Rashedi V, Gholami Tehrani L, Daroei A. Comparison of reading comprehension and working memory in hearing-impaired and normal-hearing children. Bimon Audit Tehran Univ Med Sci 2013;22:67-74.

18) Shamsian F, Simashirazi T, Nilipoor R, Karimlu M. Evaluation and comparison of consonant production in cochlear-implanted children [cited 2016 Jan 5]. J Res Rehabil Sci 2010;6:(2). Available from: http://en.journals.sid.ir/ViewPaper.aspx?ID=202521.

19) Kong YY, Stickney GS, Zeng FG. Speech and melody recognition in binaurally combined acoustic and electric hearing. J Acoust Soc Am 2005;117(3 Pt 1):1351-61.

20) Henry BA, Turner CW. The resolution of complex spectral patterns by cochlear implant and normal-hearing listeners. J Acoust Soc Am 2003;113:2861-73. 